\title{
Spatial-temporal evolution of the relationship between agricultural material inputs and agricultural greenhouse gas emissions: experience from China 2003-2018
}

\author{
Bo Sun ${ }^{1} \cdot$ Xiaocang $\mathrm{Xu}^{1,2}$ (1)
}

Received: 27 July 2021 / Accepted: 9 February 2022 / Published online: 16 February 2022

(c) The Author(s), under exclusive licence to Springer-Verlag GmbH Germany, part of Springer Nature 2022

\begin{abstract}
Agricultural materials input (fertilizer and pesticide, etc.), together with straw burning, rice planting, and livestock breeding, constitute the sources of agricultural greenhouse gas (GHG) emissions. However, most related studies have discussed the total amount of agricultural GHG emissions or the role of straw burning and rice planting in agricultural GHG emissions and few studies on agricultural GHG emissions from Agricultural materials. Based on the data of 31 provinces in China from 2003 to 2018, this paper explored the evolution process of agricultural GHG emissions from Agricultural materials. Our research turned up some interesting findings. For example, firstly, Agricultural materials play an increasingly important role in agricultural GHG emissions. Agricultural GHG emissions due to Agricultural materials account for an increasing proportion of the total agricultural GHG emissions. Secondly, there are regional differences in the evolution trend of agricultural GHG emissions caused by agricultural materials. Especially after the urbanization rate broke through the critical line of 50\% around 2010 in China.
\end{abstract}

Keywords Agricultural greenhouse gas (GHG) emissions · Agricultural materials · Chemical fertilizer · Pesticide

\section{Introduction}

In recent years, public health accidents such as Covid-19 have seriously harmed human health and caused countries worldwide to explore the causes of human health problems from the perspective of environmental pollution or greenhouse gas (GHG) emissions. The State of Food and Agriculture pointed out that about $20 \%$ of the greenhouse gases in the world come from agricultural Carbon Emissions in 2016 (Food and Agriculture Organization 2018). With the advancement of agricultural modernization and an increase use of agricultural material input, agricultural greenhouse

Responsible Editor: Ilhan Ozturk

Xiaocang Xu

03122@zjhu.edu.cn

Bo Sun

02761@zjhu.edu.cn

1 School of Economics and Management, Huzhou University, Huzhou 313000, China

2 Department of Actuarial Studies \& Business Analytics, Macquarie University, Sydney 2109, Australia gas emissions seriously affect the climate and environment (Bai et al. 2019) and threaten the safety of agricultural products and increase the risk uncertainty of agricultural management and development (Ozturk et al. 2021). Therefore, in recent years, China has successively promulgated the Cleaner Production Promotion Law of the People's Republic of China (Cleaner Production Promotion Law of the People's Republic of China, 2013) and several opinions on comprehensively deepening rural reform and accelerating agricultural modernization. Agricultural greenhouse gas emissions are not only directly from agricultural production and irrigation, but also indirectly from agricultural inputs such as chemical fertilizers and pesticides (Chandio et al. 2021). Agricultural material inputs (such as chemical fertilizer, pesticide, agricultural film, diesel) together with straw burning, rice planting, and livestock breeding constitute the main sources of agricultural greenhouse gas emissions. Therefore, it is necessary to analyze the relationship between agricultural inputs and agricultural greenhouse gas emissions on the basis of scientific calculations of agricultural greenhouse gas emissions.

The research on the measurement of agricultural greenhouse gas emissions and their influencing factors has been 
quite rich. First of all, for the selection of agricultural greenhouse gas emission sources, each scholar has a different depth. Most scholars choose agricultural materials, rice planting, livestock, and poultry breeding as greenhouse gas emission sources (West and Marland 2002; Johnson 2007; $\mathrm{Wu}$ and Feng 2019). Some scholars put straw burning and soil $\mathrm{N}_{2} \mathrm{O}$ into the standard carbon into the agricultural greenhouse gas emission measurement system (Ogbonnaya and Semple 2013; Tan 2011; Xu et al. 2020). Second, some scholars also fully consider the differences between regions when calculating agricultural greenhouse gas emissions. For example, different varieties of rice have different greenhouse gas emission coefficients in different provinces (Tallarico and Johnson 2010). Thirdly, different research methods are used to study the influencing factors of agricultural greenhouse gas emissions. For example, as shown in Table 1, Tallarico and Johnson. (2010), Wang et al. (2012), Huang et al. (2016), and Feng and Gao (2019) used STIRPAT multivariate model to empirically analyze the influencing factors of agricultural greenhouse gas emissions in different regions.

However, most of the related studies have discussed the total amount of agricultural greenhouse gas emissions, or the role of straw burning and rice planting in agricultural greenhouse gas emissions, while few kinds of literature have discussed the relationship between agricultural inputs and agricultural greenhouse gas emissions. A large number of agricultural materials are used in the production of agricultural products, such as various fertilizers, pesticides, diesel oil, and film. Taking nitrogen fertilizer as an example, China is the largest consumer of nitrogen fertilizer, consuming about $37 \%$ of the nitrogen fertilizer used for agricultural production in the world, which is about 4500 tons (Peng et al. 2002). A large-scale survey conducted in China shows that one-third of farmers use more than $250 \mathrm{~kg} \mathrm{~N} / \mathrm{ha}$ of nitrogen fertilizer to grow rice (Huang and Tang 2010). In the past 30 years, agricultural output has increased steadily due to the increase of nitrogen fertilizer application. However, the nitrogen use efficiency of agricultural production in China is low, only 35\% (MAPRC (Ministry of Agriculture of the People's Republic of China). 2013), resulting in a large number of agricultural greenhouse gas emissions in the form of soil, air, and water pollution (Ghimire et al. 2017). Chen and Zhang. (2010) found that nitrogen application accounted for the largest proportion of greenhouse gas emissions (53-57\%) in crop production in China. Yan et al. (2015) also found that greenhouse gas emissions from wheat and maize in China were significantly correlated with the nitrogen application rate. However, few studies on the effects of nitrogen fertilizer, pesticides, and other inputs on GHG emissions from agricultural production. For example, Tian and Zhang (2014) showed that agricultural resource utilization, biological and paddy bio combustion, agricultural materials, and agricultural wastes are the main sources of agricultural GHG emissions. Li et al. (2011) calculated China's agricultural GHG emissions from 1993 to 2008 based on GHG emission sources in agricultural production such as chemical fertilizer, pesticide, agricultural film, diesel oil, farming, and agricultural irrigation. It is found that agricultural greenhouse gas emissions in China have been on the rise since 1993..

To sum up, the research on agricultural GHG emissions mainly focuses on the measurement and influencing factors of agricultural GHG emissions. Among the sources of agricultural GHG emissions, many works of literature have studied the role of straw burning and rice planting in agricultural GHG emissions, while few kinds of literature have discussed the relationship between the inputs of agricultural materials (fertilizers, pesticides, plastic film, diesel, etc.) and agricultural GHG emission alone. The increase of GHG emission pressure in Chinese agriculture is closely related to the increase of dependence on agricultural materials inputs. Based on the data of 31 provinces in China from 2003 to 2018, this paper analyzes the temporal and spatial evolution of the relationship between agricultural materials inputs and agricultural GHG emissions.

\section{Materials and methods}

\section{Calculation of agricultural GHG emissions}

Refer to the research of Huang et al. (2019), we identified straw burning, Livestock breeding, rice planting, and agricultural materials as agricultural GHG emission sources, and constructed corresponding calculation formulas for agricultural GHG emissions, as shown in Eq. 1.

$E=\sum_{i=1}^{n} E_{i}=\sum_{i=1}^{n}$ Input $_{i} *$ Coef $_{i}$

In Eq. (1), $E$ is the amount of agricultural greenhouse gas emissions, $i$ represented the sources of agricultural greenhouse gas emissions, Input is the scale of emission sources, and Coef $_{i}$ represented the emissions coefficients of the $i$ emissions sources.

The central element in Eq. (1) is the coefficient of different agricultural greenhouse gas emissions sources, which is listed in Table 2.

There are four agricultural GHG emissions sources in Table 2. Firstly, straw burning, which includes wheat, rice, and rapeseed, remains an important source of agricultural GHG emissions, although the use of straw burning has been sharply reduced since China's aggressive push for cleaner agricultural production in 2012. Secondly, the GHG emissions from livestock breeding are mainly from $\mathrm{CH}_{4}$ and $\mathrm{N}_{2} \mathrm{O}$ produced by manure processing and intestinal fermentation. Because the feeding 


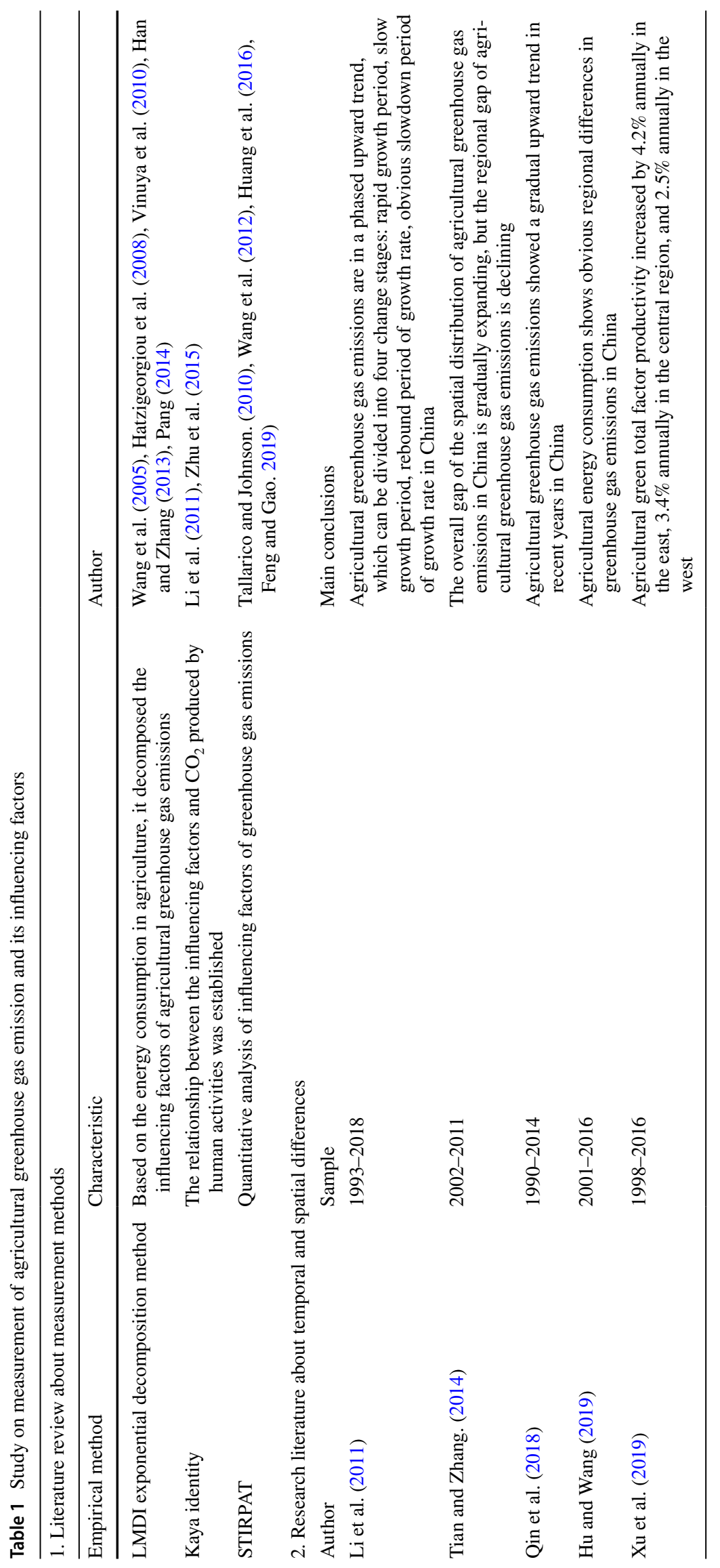


Table 2 Emission coefficients of different agriculture greenhouse gas emissions sources

\begin{tabular}{|c|c|c|c|c|c|c|c|}
\hline \multicolumn{2}{|c|}{ Emissions sources } & \multirow{2}{*}{$\begin{array}{l}\text { Unit } \\
\mathrm{kgCO}_{2} \text {-eq } / \mathrm{kg}\end{array}$} & \multirow{2}{*}{$\begin{array}{l}\text { Coefficients } \\
0.18\end{array}$} & \multicolumn{2}{|l|}{ Emissions sources } & \multirow{2}{*}{$\begin{array}{l}\text { Unit } \\
\text { kg/each head }\end{array}$} & \multirow{2}{*}{$\begin{array}{l}\text { Coefficients } \\
84\end{array}$} \\
\hline Straw burning & Rice & & & Livestock breeding & Cow & & \\
\hline & Wheat & $\mathrm{kgCO}_{2}$-eq $/ \mathrm{kg}$ & 0.16 & & Water buffalo & $\mathrm{kg} / \mathrm{each}$ head & 57 \\
\hline & Corn & $\mathrm{kgCO}_{2}$-eq $/ \mathrm{kg}$ & 0.17 & & Scalpers & $\mathrm{kg} / \mathrm{each}$ head & 48.8 \\
\hline & Rapeseed & $\mathrm{kgCO}_{2}$-eq $/ \mathrm{kg}$ & 0.22 & & Camel & $\mathrm{kg} / \mathrm{each}$ head & 47.92 \\
\hline & Soybean & $\mathrm{kgCO}_{2}$-eq $/ \mathrm{kg}$ & 0.15 & & Horse & $\mathrm{kg} / \mathrm{each}$ head & 19.64 \\
\hline & Cotton & $\mathrm{kgCO}_{2}$-eq $/ \mathrm{kg}$ & 0.13 & & Pig & & 4.5 \\
\hline \multirow[t]{4}{*}{ Rice planting } & Early rice & $\mathrm{g} / \mathrm{m}^{2}$ & 14.66 & Agricultural materials & Fertilizer & $\mathrm{kgCO}_{2}$-eq $/ \mathrm{kg}$ & 0.89 \\
\hline & Late rice & $\mathrm{g} / \mathrm{m}^{2}$ & 29.83 & & Pesticide & $\mathrm{kgCO}_{2}$-eq $/ \mathrm{kg}$ & 4.93 \\
\hline & Mid-season rice & $\mathrm{g} / \mathrm{m}^{2}$ & 33.25 & & Plastic film & $\mathrm{kgCO}_{2}$-eq $/ \mathrm{kg}$ & 5.18 \\
\hline & & & & & Diesel & $\mathrm{kgCO}_{2}$-eq $/ \mathrm{kg}$ & 0.59 \\
\hline
\end{tabular}

Data comes from ORNL (American Oak Ridge National Laboratory 2009), IPCC (Intergovernmental Panel on Climate Change 2013) report. This table only lists the relatively large amount of pollution sources.)

cycle of livestock and poultry is different, the feeding amount needs to be adjusted properly when calculating. For example, the average life cycle of pigs, rabbits, and poultry is 200 days, 105 days, and 55 days, respectively, and the feeding rate is greater than 1. The IPCC report chose $\mathrm{CH}_{4}$ and $\mathrm{N}_{2} \mathrm{O}$ emissions from the most important animals in farming as its calculation system. Thirdly, the GHG emission from rice planting is mainly $\mathrm{CH}_{4}$. Due to the difference of $\mathrm{CH}_{4}$ in different rice varieties, the factors of rice varieties should be taken into account when calculating the GHG emission from rice plantings, such as single-cropping or double-cropping rice Zhang and $\mathrm{Xu}$. (2021). Finally, GHG emissions from agricultural material inputs consist of two components. One is the GHG produced by direct inputs such as fertilizers, pesticides, and plastic film. The second is the GHG produced by the consumption of energy such as diesel (Appendix Table 4).

In this paper, $\mathrm{kgCO}_{2}$-eq is used as a unified measurement unit for agricultural greenhouse gas emissions.

\section{Data source}

This paper selects the relevant data of 31 provinces in China (except Hong Kong, Macao, and Taiwan) from 2003 to 2018 to calculate agricultural greenhouse gas emissions. The input data of agricultural means (fertilizer, plastic film, diesel) in the process of agricultural production are from the national agricultural cost and benefit data collection and China Agricultural Statistical Yearbook.

Table 3 lists the input amount of agricultural materials of 31 provinces in 2003, 2010, and 2018.

\section{Results}

\section{Overall changing trend}

\section{Nationwide analysis}

Through the calculation method of agricultural greenhouse gas emissions, agricultural greenhouse gas emissions from 2003 to 2018 are calculated, as shown in Figs. 1 and 2.

Two important pieces of information were shown in Fig. 1.

Firstly, agricultural GHG emissions experienced an "inverted U" trend of first increasing and then decreasing (321.6863 million tons in 2003, 379.9784 million tons in $2015,341.8553$ million tons in 2018). This may have something to do with the promotion of the policy of "opinions on comprehensively deepening rural reform and accelerating agricultural modernization" recently issued by the State Council of China in 2014. It shows that China's agricultural economy is developing vigorously during this period, while the government's "carbon emission reduction" policy on agriculture has a positive effect, and the agricultural production efficiency has been improved.

Secondly, similar to the temporal trend, among the studied emission sources, GHG emissions from agricultural materials showed an "inverted U" shaped trend, increased at first (in 2003), and then declined in 2018, and the turning point is exactly 2015, which indicates that the impact of agricultural material input on agricultural GHG emissions is very large. On the other hand, straw burning showed an increasing trend, livestock brewing showed a decreasing trend, and rice planting remained stable. 
Table 3 The input amount of agricultural materials during 2003-2018 in different provinces (units: 10,000 tons)

\begin{tabular}{|c|c|c|c|c|c|c|c|c|c|c|c|}
\hline Regions & Year & $\mathrm{Fe}$ & $\mathrm{Pe}$ & $\mathrm{Pl}$ & Di & Regions & Year & $\mathrm{Fe}$ & $\mathrm{Pe}$ & $\mathrm{Pl}$ & Di \\
\hline \multirow[t]{3}{*}{ Beijing } & 2003 & 14.3 & 0.52 & 1.44 & 7.1 & \multirow[t]{3}{*}{ Hubei } & 2003 & 270.3 & 9.98 & 6.76 & 39.3 \\
\hline & 2010 & 13.7 & 0.39 & 1.35 & 3.9 & & 2010 & 350.8 & 13.99 & 6.37 & 58.3 \\
\hline & 2018 & 7.3 & 0.25 & 0.82 & 1.9 & & 2018 & 295.8 & 10.33 & 6.35 & 65.1 \\
\hline \multirow[t]{3}{*}{ Tianjin } & 2003 & 17.8 & 0.25 & 1.29 & 11.3 & \multirow[t]{3}{*}{ Hunan } & 2003 & 188.3 & 9.53 & 5.06 & 27.7 \\
\hline & 2010 & 25.5 & 0.37 & 1.20 & 17 & & 2010 & 236.6 & 11.87 & 7.31 & 37.8 \\
\hline & 2018 & 16.9 & 0.21 & 0.90 & 2.2 & & 2018 & 242.6 & 11.41 & 8.53 & 44.6 \\
\hline \multirow[t]{3}{*}{ Hebei } & 2003 & 283.3 & 7.52 & 8.90 & 255.9 & \multirow[t]{3}{*}{ Guangdong } & 2003 & 199.6 & 8.60 & 3.20 & 60.4 \\
\hline & 2010 & 322.9 & 8.46 & 11.86 & 298.5 & & 2010 & 237.3 & 10.43 & 4.21 & 75.3 \\
\hline & 2018 & 312.4 & 6.14 & 10.98 & 217.6 & & 2018 & 231.3 & 9.36 & 4.48 & 88.5 \\
\hline \multirow[t]{3}{*}{ Shanxi } & 2003 & 89.9 & 1.95 & 2.91 & 24.1 & \multirow[t]{3}{*}{ Guangxi } & 2003 & 183.7 & 4.97 & 2.05 & 46.4 \\
\hline & 2010 & 110.4 & 2.61 & 3.88 & 29.3 & & 2010 & 237.2 & 6.44 & 3.51 & 58.1 \\
\hline & 2018 & 109.6 & 2.65 & 4.90 & 27.6 & & 2018 & 255 & 6.97 & 4.71 & 52.7 \\
\hline \multirow[t]{3}{*}{ Inner Mongolia } & 2003 & 93.2 & 1.05 & 3.20 & 34.9 & \multirow[t]{3}{*}{ Hainan } & 2003 & 33.9 & 1.34 & 0.50 & 14.6 \\
\hline & 2010 & 177.2 & 2.43 & 6.05 & 65.3 & & 2010 & 46.4 & 4.55 & 1.60 & 22.4 \\
\hline & 2018 & 222.7 & 2.95 & 9.39 & 79.2 & & 2018 & 48.4 & 2.32 & 2.35 & 20.6 \\
\hline \multirow[t]{3}{*}{ Liaoning } & 2003 & 112.6 & 4.45 & 8.03 & 48.9 & \multirow[t]{3}{*}{ Chongqing } & 2003 & 71.6 & 1.95 & 2.42 & 12.6 \\
\hline & 2010 & 140.1 & 6.93 & 12.53 & 72 & & 2010 & 91.8 & 2.08 & 3.66 & 16.4 \\
\hline & 2018 & 145 & 5.50 & 11.79 & 62.4 & & 2018 & 93.2 & 1.71 & 4.46 & 21.4 \\
\hline \multirow[t]{3}{*}{ Ji Lin } & 2003 & 122.3 & 2.35 & 4.27 & 34.9 & \multirow[t]{3}{*}{ Sichuan } & 2003 & 208.4 & 5.38 & 8.17 & 33.8 \\
\hline & 2010 & 182.8 & 4.27 & 5.25 & 61 & & 2010 & 248 & 6.21 & 11.41 & 42.1 \\
\hline & 2018 & 228.3 & 5.09 & 5.62 & 67.3 & & 2018 & 235.2 & 5.12 & 12.01 & 46.9 \\
\hline \multirow[t]{3}{*}{ Heilongjiang } & 2003 & 125.7 & 3.65 & 4.98 & 85.4 & \multirow[t]{3}{*}{ Guizhou } & 2003 & 74.9 & 0.90 & 2.46 & 4.5 \\
\hline & 2010 & 214.9 & 7.37 & 6.93 & 127.9 & & 2010 & 86.5 & 1.29 & 3.61 & 6.9 \\
\hline & 2018 & 245.6 & 7.41 & 7.74 & 147.4 & & 2018 & 89.5 & 1.11 & 5.50 & 11.1 \\
\hline \multirow[t]{3}{*}{ Shanghai } & 2003 & 15.9 & 0.85 & 2.24 & 10.3 & \multirow[t]{3}{*}{ Yunnan } & 2003 & 129.2 & 2.68 & 6.15 & 44.6 \\
\hline & 2010 & 11.8 & 0.70 & 2.11 & 14.8 & & 2010 & 184.6 & 4.61 & 8.56 & 65.3 \\
\hline & 2018 & 8.4 & 0.31 & 1.47 & 13.1 & & 2018 & 217.4 & 5.25 & 11.96 & 25.4 \\
\hline \multirow[t]{3}{*}{ Jiangsu } & 2003 & 334.7 & 8.79 & 6.96 & 76.3 & Tibet & 2003 & 3.2 & 0.05 & 0.05 & 0.8 \\
\hline & 2010 & 341.1 & 9.01 & 10.01 & 97.5 & & 2010 & 4.7 & 0.10 & 0.08 & 3.1 \\
\hline & 2018 & 292.5 & 6.96 & 11.60 & 109.4 & & 2018 & 5.2 & 0.09 & 0.17 & 3 \\
\hline Zhejiang & 2003 & 90.4 & 6.16 & 4.24 & 175.8 & Shaanxi & 2003 & 142.7 & 0.97 & 2.17 & 42.6 \\
\hline & 2010 & 92.2 & 6.50 & 5.54 & 191.6 & & 2010 & 196.8 & 1.24 & 3.68 & 70.4 \\
\hline & 2018 & 77.8 & 4.37 & 6.87 & 198.8 & & 2018 & 229.6 & 1.25 & 4.41 & 92.6 \\
\hline Anhui & 2003 & 281.3 & 7.88 & 6.75 & 47.4 & Gansu & 2003 & 69.6 & 1.27 & 7.72 & 19.2 \\
\hline & 2010 & 319.8 & 11.66 & 8.07 & 68.1 & & 2010 & 85.3 & 4.45 & 12.37 & 29 \\
\hline & 2018 & 311.8 & 9.41 & 9.78 & 75.5 & & 2018 & 83.2 & 4.28 & 16.12 & 40.8 \\
\hline Fujian & 2003 & 120.3 & 5.52 & 2.64 & 80.6 & Qinghai & 2003 & 6.9 & 0.16 & 0.09 & 5.1 \\
\hline & 2010 & 121 & 5.82 & 5.70 & 83.2 & & 2010 & 8.8 & 0.20 & 0.31 & 6.1 \\
\hline & 2018 & 110.7 & 4.91 & 6.00 & 82.4 & & 2018 & 8.3 & 0.17 & 0.75 & 6.4 \\
\hline Jiangxi & 2003 & 111 & 5.34 & 3.39 & 17.3 & Ningxia & 2003 & 25.4 & 0.16 & 0.59 & 12 \\
\hline & 2010 & 137.6 & 10.65 & 4.54 & 24.9 & & 2010 & 37.9 & 0.26 & 1.40 & 20.2 \\
\hline & 2018 & 123.2 & 7.71 & 5.22 & 30.9 & & 2018 & 38.4 & 0.22 & 1.49 & 21.7 \\
\hline Shandong & 2003 & 432.7 & 17.08 & 30.56 & 172.2 & Xinjiang & 2003 & 90.7 & 1.21 & 9.93 & 44.4 \\
\hline & 2010 & 475.3 & 16.49 & 32.29 & 186.6 & & 2010 & 167.6 & 1.81 & 17.07 & 62.3 \\
\hline & 2018 & 420.3 & 12.98 & 27.69 & 147.5 & & 2018 & 255 & 2.37 & 26.98 & 95.5 \\
\hline Henan & 2003 & 467.9 & 9.86 & 9.88 & 84.6 & & & & & & \\
\hline & 2010 & 655.2 & 12.48 & 14.69 & 107.9 & & & & & & \\
\hline & 2018 & 692.8 & 11.36 & 15.28 & 103.9 & & & & & & \\
\hline
\end{tabular}

$\mathrm{Fe}=$ Fertilizer, $\mathrm{Pe}=$ Pesticide, $\mathrm{Pl}=$ Plastic film, $\mathrm{Di}=$ Diesel 
Fig. 1 Temporal evolution of agricultural GHG emissions in China during 2003-2018 (units: 10,000 tons. The right-hand ordinate is the total agricultural GHG emissions)

Fig. 2 Regional differences in agricultural greenhouse gas emissions in China during 2003-2018 (units: 10,000 tons). a The largest greenhouse gas emission region: Henan. b The least greenhouse gas emission region: Beijing
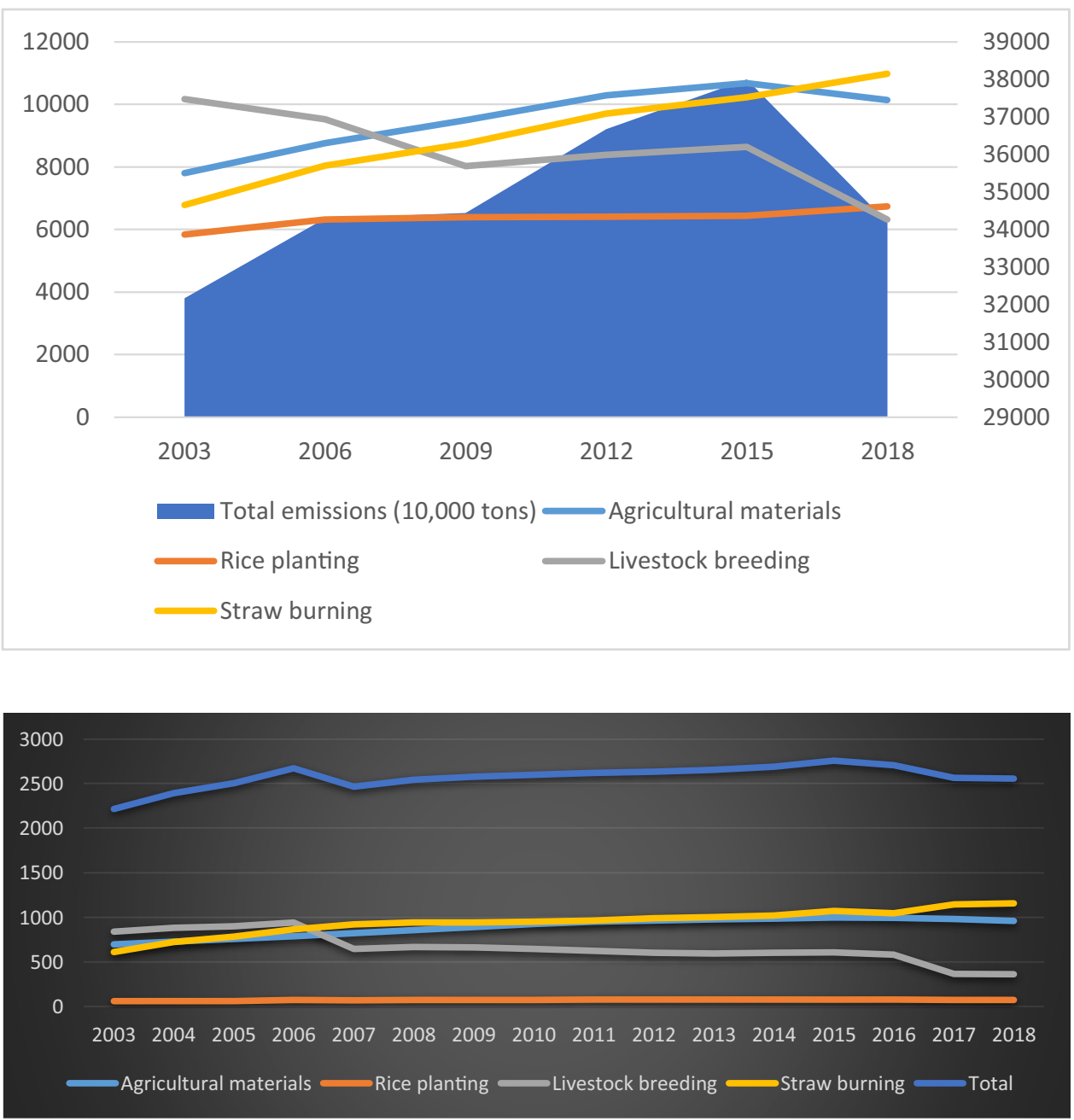

(a)

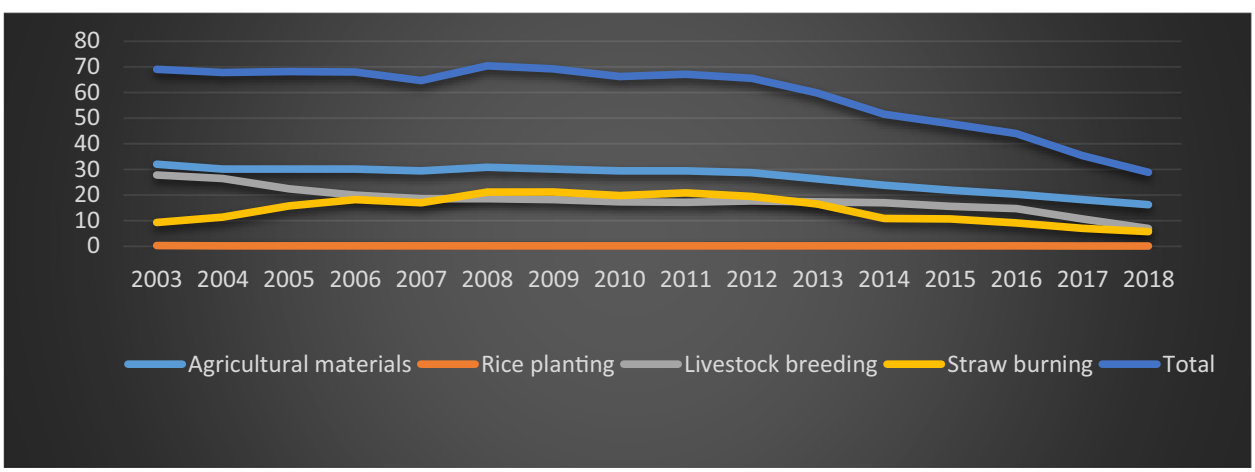

(b)

\section{Regional comparison}

The situation of agricultural production in different provinces of China is different, so the total amount of agricultural greenhouse gas emissions in each province is also quite different. For example, in 2018, the five provinces with the largest greenhouse gas emissions are Henan,
Shandong, Heilongjiang, Jiangsu, and Anhui. The five provinces with the smallest greenhouse gas emissions are Beijing, Shanghai, Tianjin, Ningxia, and Hainan. Among them, greenhouse gas emissions ranked first in Henan, which is 55 times of Beijing, which shows that agricultural carbon emissions vary greatly among provinces in China. The provinces with large agricultural greenhouse 
gas emissions are all traditional agricultural provinces and major grain-producing areas in China. However, most agricultural development in these areas mainly pursues the high yield of grain, and the mode is relatively single, leading to a large amount of greenhouse gas emissions. In Fig. 2, we take Henan Province, which has the largest greenhouse gas emissions, and Beijing, which has the smallest greenhouse gas emissions.

Moreover, Fig. 3 shows the proportion of greenhouse gas emissions from agricultural material inputs in total agricultural GHG emissions in different regions during 2003-2018.

As shown in Fig. 3, the five provinces with the smallest proportion of greenhouse gas emissions from agricultural material input in total agricultural greenhouse gas emissions in 2018 are Tibet, Qinghai, Jiangxi, Hunan, and Sichuan. The largest five provinces are Beijing, Shaanxi, Xinjiang, Fujian, and Hebei.

\section{Changing trend of internal structure}

Figure 4 shows the agricultural greenhouse gas emissions from fertilizer, pesticide, plastic film, and diesel in 2003 and 2018.

As can be seen from Fig. 4, greenhouse gas emissions from fertilizer, pesticide, and diesel decreased from 2003 to 2018 , only plastic film increased from 2003 to 2018 , indicating that since China began to implement the cleaner production policy in 2003, agricultural cleaner production has made great progress, and the utilization efficiency of fertilizer, pesticide, and diesel is improving. The understanding and control of their environmental pollution have also been further improved.

Furthermore, the internal structure of greenhouse gas emissions from agricultural materials in different regions also shows some regional differences.
Fig. 3 The proportion of greenhouse gas emissions from agricultural materials in total agricultural GHG emissions. Note: the symbol "I" in the figure is the standard deviation
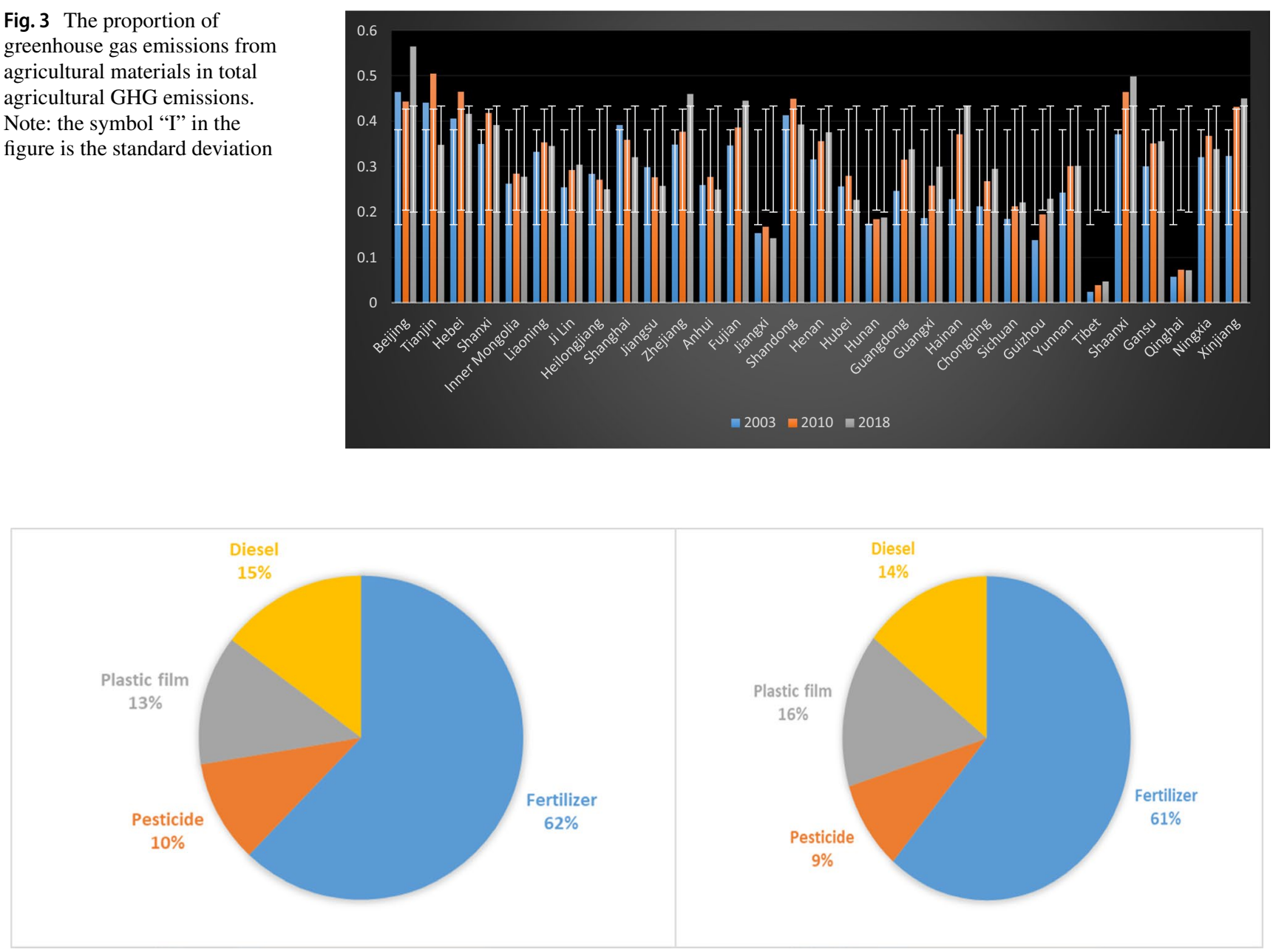

2003
2018

Fig. 4 The internal structure of greenhouse gas emissions from agricultural material 2003, 2018. (units: \%) 
As shown in Fig. 5, taking 2018 as an example, the three smallest provinces of greenhouse gas emissions from fertilizer were Tibet (4.66), Beijing (6.54), and Qinghai (7.44), respectively. The smallest five provinces of greenhouse gas emissions from pesticide were Tibet (0.48), Qinghai (0.88), Tianjin (1.08), Ningxia (1.11), Beijing (1.27), and the largest three provinces of greenhouse gas emissions from pesticide were Shandong (64.08), Hunan (56.32), and Henan (56.05). The smallest three provinces of greenhouse gas emissions from diesel were Beijing (1.12), Tianjin (1.30), and Tibet (1.77), and the largest three provinces of greenhouse gas emissions from diesel were Hebei (128.97), Shan Dong (87.42), and Heilongjiang (87.36)..

\section{Economic negative output analysis}

Greenhouse gas emissions have a negative effect on agricultural production, so they have a certain discount on the effective output of agriculture. Figure 6 shows the proportion of GHG emissions from agricultural materials inputs to the agricultural output value, which can be used to represent the economic negative output of agricultural materials inputs.
Fig. 5 Internal structure of greenhouse gas emissions from agricultural material in different regions (the $Y$ axis shows the proportion of different agricultural materials)

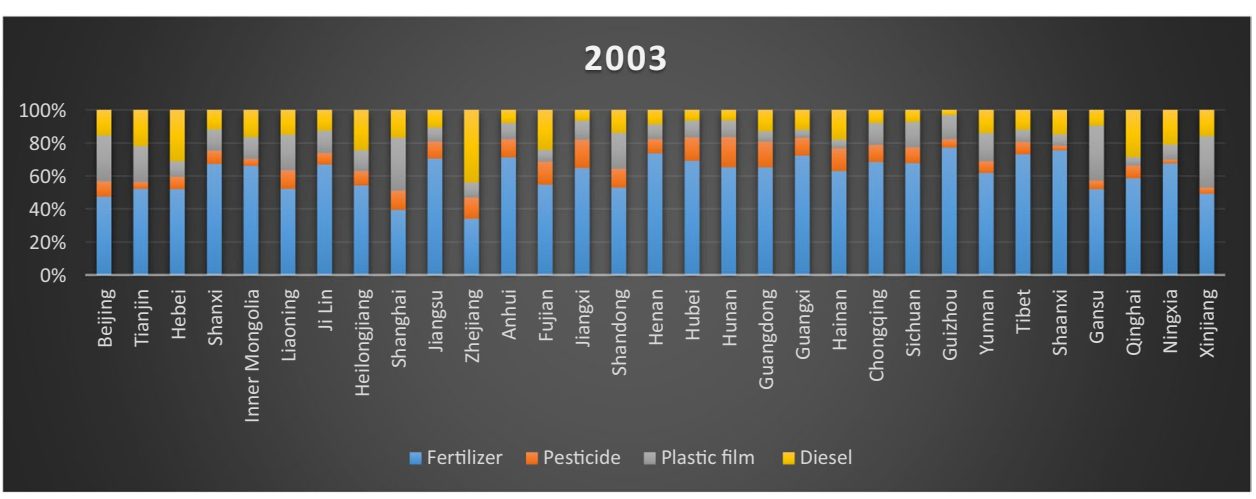

(a)

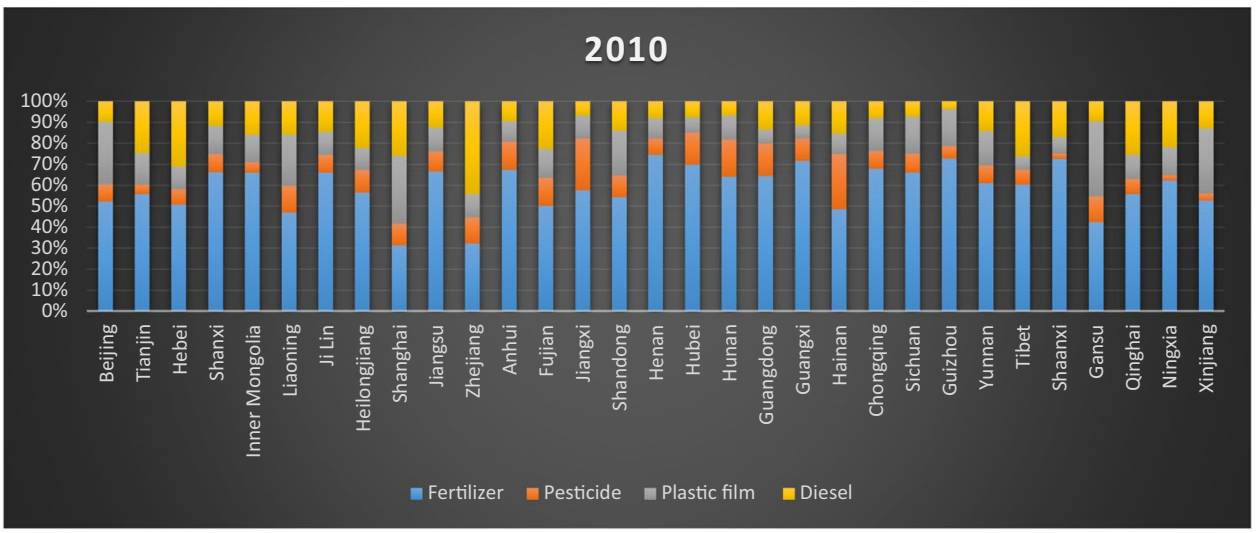

(b)

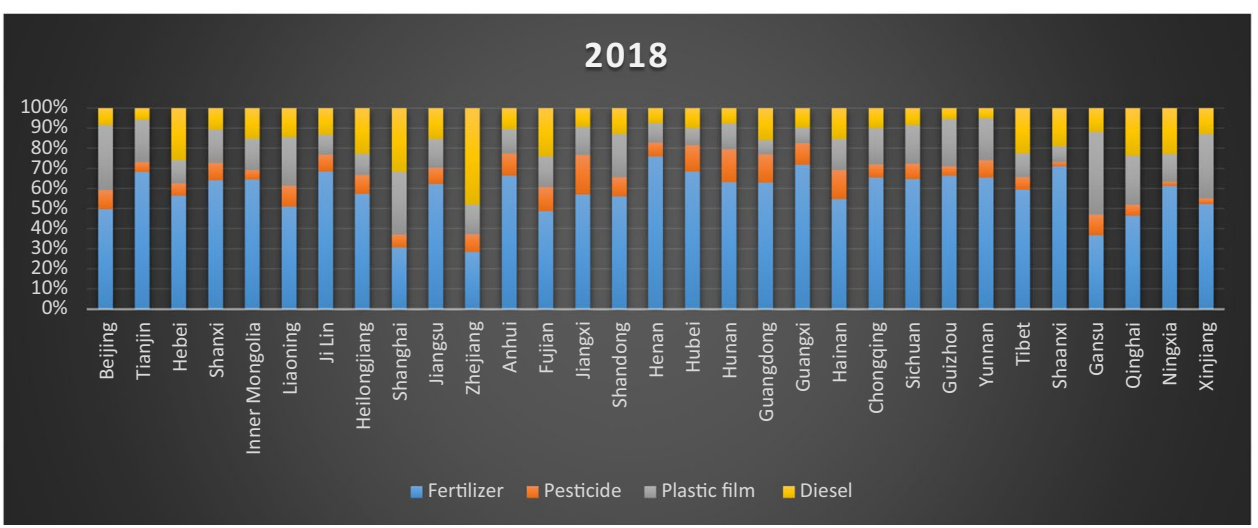

(c) 
Fig. 6 The proportion of GHG emissions from agricultural materials to agricultural output value (Note: the symbol "I" in the figure is the standard deviation)

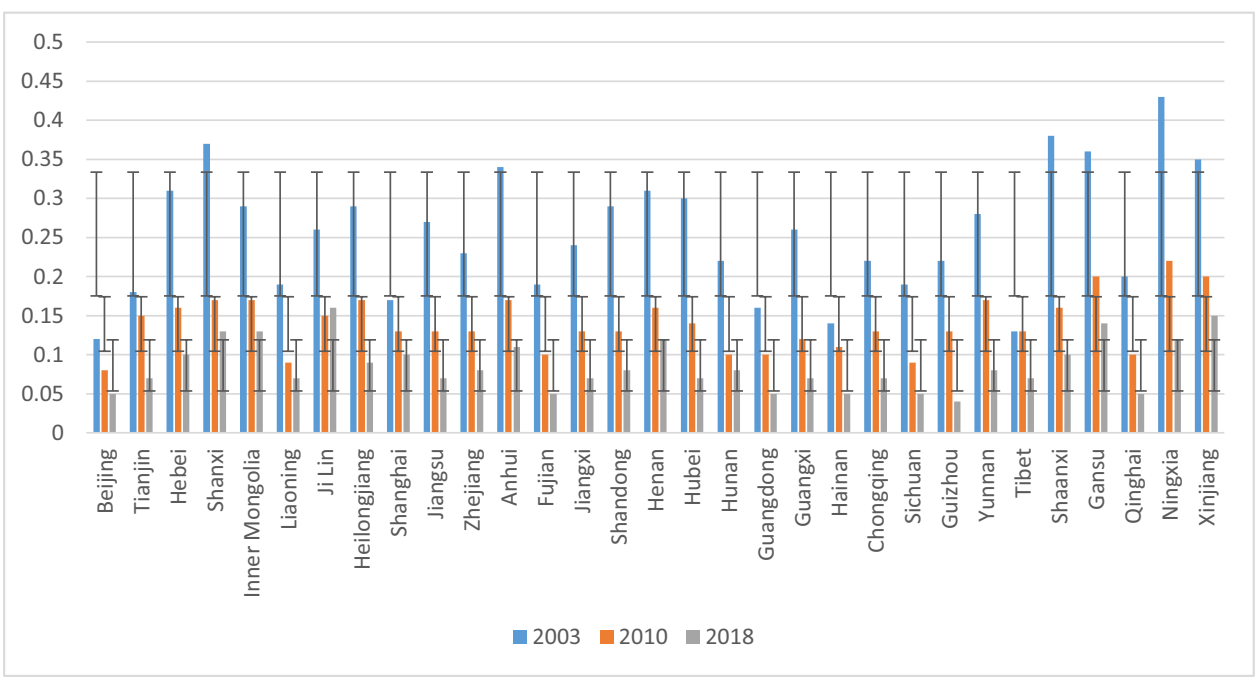

Some facts can be clearly seen from Fig. 6 and the standard deviation in Fig. 6. Firstly, the proportion of greenhouse gas emissions from agricultural materials inputs to the agricultural output value of all provinces showed a decreasing trend from 2003 to 2018. For example, Beijing dropped from 0.12 in 2003 to 0.08 in 2010 and then to 0.05 in 2018, in Henan Province, from 0.31 in 2003 to 0.16 in 2010, and then to 0.12 in 2018. Secondly, in 2018, Guizhou, Beijing, Guangdong, Tianjin, and Jiangxi are the five provinces with the smallest proportion of greenhouse gas emissions from agricultural inputs in agricultural output value. The largest five provinces are Jilin, Xinjiang, Gansu, Shanxi, and Inner Mongolia.

\section{Discussion}

Although together with straw burning, rice planting, and livestock breeding constitutes the source of agricultural GHG emissions, there are few studies on the relationship between agricultural material inputs (such as chemical fertilizers and pesticides) and agricultural GHG emissions. Based on the data of 31 provinces in China from 2003 to 2018 , this paper analyzes the temporal and spatial evolution of the relationship between agricultural material inputs and agricultural GHG emissions. Some interesting information was found.

Firstly, agricultural GHG emissions have significant characteristics of time evolution. First, total agricultural greenhouse gas emissions experienced an "inverted U" trend of first increasing and then decreasing. From 2003 to 2018, the total agricultural greenhouse gas emissions increased from 321.6863 million tons in 2003 to 379.9784 million tons in 2015 and then decreased rapidly to 341.8553 million tons in 2018. Second, among the four sources of agricultural greenhouse gas emissions, the agricultural greenhouse gas emissions from agricultural materials also show an "inverted U" trend of first increasing and then decreasing. From 2003 to 2018 , the turning point is just 2015 , which shows that agricultural materials input greatly impacts agricultural greenhouse gas emissions. On the other hand, straw burning showed an increasing trend, livestock brewing showed a decreasing trend, and rice planting remained stable. These spatial and temporal characteristics may be related to the policy of "opinions on comprehensively deepening rural reform and accelerating agricultural modernization" issued by the State Council of China in 2014. It shows that China's agricultural economy is developing vigorously during this period, while the government's "carbon emission reduction" policy on agriculture has a good effect, and the agricultural production efficiency has been improved. This is consistent with $\mathrm{Xu}$ et al. (2020) conclusion that the policy effect is obvious.

Secondly, the situation of agricultural production in different provinces of China is different, so the total amount of agricultural greenhouse gas emissions in each province is also quite different. For example, in 2018, the five provinces with the largest greenhouse gas emissions are Henan, Shandong, Heilongjiang, Jiangsu, and Anhui. The five provinces with the smallest greenhouse gas emissions are Beijing, Shanghai, Tianjin, Ningxia, and Hainan. Among them, greenhouse gas emissions ranked first in Henan, which is 55 times of Beijing, which shows that agricultural carbon emissions vary greatly among provinces in China. The provinces with large agricultural greenhouse gas emissions are all traditional agricultural provinces and major grain-producing areas in China. However, most agricultural development in these areas mainly pursues the high yield of grain, and the mode is relatively single, leading to a large amount of greenhouse gas emissions.

Thirdly, there are some differences in the internal structure of GHG emissions from agricultural materials from 
Table 4 Abbreviations

\begin{tabular}{ll}
\hline Full name & Abbreviation \\
\hline Greenhouse gas & GHG \\
Agricultural greenhouse gas emissions & Agricultural \\
& GHG emis- \\
sions \\
World Food and Agriculture Organization & FAO \\
American Oak Ridge National Laboratory & $\mathrm{ORNL}$ \\
Intergovernmental Panel on Climate Change & $\mathrm{IPCC}$ \\
Carbon dioxide & $\mathrm{CO}_{2}$ \\
Methane & $\mathrm{CH}_{4}$ \\
Nitrous oxide & $\mathrm{N}_{2} \mathrm{O}$ \\
\hline
\end{tabular}

2003 to 2018. First, greenhouse gas emissions from fertilizer, pesticide, and diesel all decreased from 2003 to 2018, only plastic film increased from 2003 to 2018, indicating that since China began to implement the cleaner production policy in 2003, agricultural cleaner production has made great progress, and the utilization efficiency of fertilizer, pesticide, and diesel is improving. The understanding and control of their environmental pollution has also been further improved. Second, the internal structure of greenhouse gas emissions from agricultural material in different regions also shows some regional differences. In 2018, for example, the three smallest provinces of greenhouse gas emissions from fertilizer were Tibet (4.66), Beijing (6.54), and Qinghai (7.44), respectively. The smallest five provinces of greenhouse gas emissions from pesticide were Tibet (0.48), Qinghai (0.88), Tianjin (1.08), Ningxia (1.11), Beijing (1.27), and the largest three provinces of greenhouse gas emissions from pesticide were Shandong (64.08), Hunan (56.32), and Henan (56.05). The smallest three provinces of greenhouse gas emissions from diesel were Beijing (1.12), Tianjin (1.30), and Tibet (1.77), and the largest three provinces of greenhouse gas emissions from diesel were Hebei (128.97), Shan Dong (87.42), and Heilongjiang (87.36). The regional differences in the internal structure of greenhouse gas emissions from agricultural materials in different regions also indicate that when formulating environ-mental pollution control policies or agricultural development policies, each province should adopt targeted treatment policies according to local conditions.

Finally, from the perspective of economic negative output of agricultural materials inputs, the proportion of GHG emissions from agricultural materials inputs to agricultural output values of all provinces showed a decreasing trend from 2003 to 2018. For example, Beijing dropped from 0.12 in 2003 to 0.08 in 2010 and then to 0.05 in 2018, in Henan Province, from 0.31 in 2003 to 0.16 in 2010, and then to 0.12 in 2018. Secondly, whether in Beijing or Henan, there is basically no correlation between agricultural greenhouse gas emissions from agricultural material and natural disasters (crop-affected area). But it has a strong reverse relationship with R\&D investment, especially after 2010. This relationship is more obvious in Beijing. It should be noted that around 2010, the urbanization rate just broke through the critical line of $50 \%$ in China. This just confirms the conclusion from Ozturk et al.(2021) that economic growth has a great impact on the environment.

In conclusion, our findings provide some policy implications for the establishment of long-term mechanisms for sustainable agricultural development. For example, the government can take comprehensive measures such as financial incentives, subsidies, and structural adjustment to strengthen the prevention and control of agricultural pollution. To be specific, first, governments should support the use of efficient fertilizers, low pesticide residues, and large-scale recycling of livestock and poultry waste. Second, governments should encourage agricultural producers to actively use organic fertilizers. Third, the government should vigorously promote the use of high standards of agricultural film and film recycling. Finally, the government should support forage and forage base variety improvement, water conservancy construction, pest control, etc. In the future, we will focus on specific aspects of Agricultural materials input, such as the impact of fertilizer or pesticide on Agricultural GHG emissions.

\section{Appendix}

\section{Please see Table 4}

Author contribution Designed the research, X.X.; conducted the data analysis: B.S.; the original draft preparation, B.S. Review the paper: X.X. Funding: X.X.

Funding This paper is funded by China Chongqing Social Science Planning Fund, grant number no: 2017QNJJ17, and Open subject of Collaborative Innovation Center for Urban Industries Development in Chengdu-Chongqing Economic Zone "Study on spatiotemporal differences and influencing factors of low carbon agricultural productivity in China" (No: 1901598).

Data availability All data generated or analyzed during the current study are presented in this article. Raw data will be also accessible from the author group if requested.

\section{Declarations}

Ethics approval and consent to participate The locations of material collected here are neither privately owned lands nor protected areas. No specific permits were required for our research.

Consent for publication Not applicable. 
Competing interests The authors declare no competing interests.

\section{References}

Bai Y, Deng X, Jiang S, Zhao Z, Miao Y (2019) Relationship between climate change and low-carbon agri-cultural production: a case study in Hebei Province. China Ecological Indicators 105:438447. https://doi.org/10.1016/j.ecolind.2018.04.003

Bai R (2013) Vigorous promotion for the mechanization of rice production in the double paddy cropping region, http://www.camn. agri.gov.cn/Html/201308 19/2 184220130819 24841.html (in Chinese).

Bo L (2012) Empirical study on relationship between economic growth and agricultural carbon emissions. Ecology and Environmental Ences 21(2):220-224

Chandio, A. A., Akram, W., Ozturk, I., Ahmad, M., \& Ahmad, F. (2021). Towards long-term sustainable environment: does agriculture and renewable energy consumption matter?. Environmental Science and Pollution Research, 1-20.

Chen GQ, Zhang B (2010) Greenhouse gas emissions in China 2007: Inventory and input-output analysis. Energy Policy 38:6180-6193

Feng Z, Gao Y (2019) A study on the driving factors, emission reduction contribution and potential of China's regional carbon emissions. Journal of Beijing Institute of Technology (social Sciences Edition) 21(04):13-20 [In Chinese]

Food and Agriculture Organization (2018) FAOSTAT database collections [EB/OL] http://www.apps.fao.org. Access time:2021.7.25.

Ghimire R, Lamichhane S, Acharya B, Bista P, Sainju U (2017) Tillage, crop residue, and nutrient management effects on soil organic carbon in rice-based cropping systems: a review. J. Integr. Agric. 16 (1): $1 \mathrm{e} 15$.

Han Y, Zhang L (2013) Research on decomposition factors of China's agricultural carbon emissions: an LMDI decomposition method based on energy consumption and trade. Contemporary Economic Research 004:47-52 [In Chinese]

Hatzigeorgiou E, Polatidis H, Haralambopoulos D (2008) CO2 emissions in Greece for 1990-2002: a decomposition analysis and comparison of results using the Arithmetic Mean Divisia Index and Logarithmic Mean Divisia Index techniques. Energy 33:492-499

Hu J, Wang Q (2019) A study on regional differences of China's agricultural energy consumption carbon emissions based on Theil index. Guizhou Soc Sci 007:108-117 [In Chinese]

Huang Y, Tang YH (2010) An estimate of greenhouse gas (N2O and $\mathrm{CO} 2$ ) mitigation potential under various scenarios of nitrogen use efficiency in Chinese croplands. Glob Change Biol 16:2958-2970

Huang R, Wang Z, Guan Q (2016) Analysis and trend prediction of influencing factors of energy consumption carbon emissions in Jiangsu Province based on STIRPAT model. Geogr Res 35(004):781-789 [In Chinese]

Huang X, Xu X, Wang Q, Zhang L, Gao X, Chen L (2019) Assessment of agricultural carbon emissions and their spatio-temporal changes in China, 1997-2016. Int J Envi-Ron Res Public Health 16:3105. https://doi.org/10.3390/ijerph16173105

IPCC (2013). In: Stocker TF, Qin D, Plattner GK, Tignor M, Allen SK, Boschung J, Nauels A, Xia Y, Bex V, Midgley PM (eds) Climate change 2013: the physical science basis, Contribution of Working Group I to the Fifth Assessment Report of the Intergovernmental Panel on Climate Change. Cambridge University Press, Cambridge, United Kingdom and New York, NY, USA, p 1535

Johnson J (2007) Agricultural opportunities to mitigate greenhouse gas emissions. Environ Pollut 150:107-124
Li B, Zhang J, Li H (2011) An empirical study on China's agricultural carbon emissions and economic development. Arid Land Resources and Environment 25(12):8-13 [In Chinese]

MAPRC (Ministry of Agriculture of the People's Republic of China) (2013) Promoting the steady improvement of fertilizers use efficiency, fertilizers use efficiency up to $33 \%$ by scientific fertilization in China. http://www.moa.gov.cn/zwllm/zwdt/201310/ t20131010 3625203.htm (in Chinese).

Ogbonnaya U, Semple KT (2013) Impact of biochar on organic contaminants in soil: a tool for mitigating risk? Agronomy 3(2):349-375

Ozturk, I., Majeed, M. T., \& Khan, S. (2021). Decoupling and decomposition analysis of environmental impact from economic growth: a comparative analysis of Pakistan, India, and China. Environmental and Ecological Statistics, 1-28.

Pang L (2014) Analysis of regional differences and influencing factors of agricultural carbon emissions in my country. Arid Land Resources and Environment 28(12):1-7 [In Chinese]

Peng S, Huang J, Zhong X, Yang J, Wang G, Zou Y, Zhang F, Zhu Q, Buresh R, Witt C (2002) Research strategy in improving fertilizernitrogen use efficiency of irrigated rice in China. Sci Agric Sin 35(9):1095-1103 (in Chinese with English Abstract)

Qin W, Jian Q, Jing B (2018) Influencing factors of agricultural carbon emission and regional differences between south and north in China. Journal of Ecology and Rural Environment 34(4):318-325

Tallarico C, Johnson A (2010) The implications of global ecological elasticities for carbon control: a STIRPAT formulation. journal of management policy \& practice. 11(4):86-94.

Tan Q (2011)Agricultural greenhouse gas emissions in China: status and challenges. China Population - Resources and Environment. 21(10):69-75. (in Chinese)

The Standing Committee of the National People's Congress (2013) Cleaner production promotion law of the People's Republic of China. http://www.mee.gov.cn/ywgz/fgbz/fl/201904/t20190428_ 701287.shtml.

Tian Y, Zhang J (2014) Research on spatial-temporal characteristics and driving factor of agricultural carbon emissions in China. J Integr Agric 13(6):1393-1403. https://doi.org/10.1016/s20953119(13)60624-3

Vinuya F, Difurio R, Sandoval R (2010) A decomposition analysis of $\mathrm{CO}_{2}$ emissions in the United States. Appl Econ Lett 17(10-12):925-931

Wang C, Chen J, Zou J (2005) Decomposition of energy-related $\mathrm{CO}_{2}$ emission in China: 1957-2000. Energy 30(1):73-83

Wang Z, Yin F, Zhang Y (2012) An empirical research on the influencing factors of regional $\mathrm{CO}_{2}$ emissions: evidence from Beijing city. China Applied Energy 100:277-284

West T, Marland G (2002) A synthesis of carbon sequestration, carbon emissions, and net carbon flux in agriculture: comparing tillage practices in the United States. Agr Ecosyst Environ 91(1-3):217232. https://doi.org/10.1016/S0167-8809(01)00233-X

Wu Y, Feng K (2019) Spatial-temporal differentiation features and correlation effects of provincial agricultural carbon emissions in China. Environ Sci Technol 42(3):180-190 (in Chinese)

Xu X, Huang X, Huang J, Gao X, Chen L (2019) Spatial-temporal characteristics of agriculture green total factor productivity in China, 1998-2016: based on more sophisticated calculations of carbon emissions. Int J Environ Res Public Health 16:3932. https://doi. org/10.3390/ijerph16203932

$\mathrm{Xu}$ X, Zhang L, Chen L, Liu C (2020) The role of soil $\mathrm{N}_{2} \mathrm{O}$ emissions in agricultural green total factor productivity: an empirical study from China around 2006 when agricultural tax was abolished. Agriculture 10:150. https://doi.org/10.3390/agriculture10050150

Yan M, Cheng K, Luo T, Yan Y, Pan G, Rees R (2015) Carbon footprint of grain crop production in China-based on farm survey data. $\mathrm{J}$ Clean pro 104:130-138 
Yun T, Jun Z, Ya E (2014) Research on spatial-temporal characteristics and driving factor of agricultural carbon emissions in China. $\mathrm{J}$ Integr Agric 13(006):1393-1403

Zhang L, Xu X (2021) Difference in carbon footprint between single- and double-cropping rice production in China, 2003-2016. Environ Sci Pollut Res 28:27308

Zhu X, Wang K, Wang P (2015) A study on the staged driving factors of carbon emission growth. Economic Develop-Ments 657(11):79-89 [In Chinese]
Publisher's note Springer Nature remains neutral with regard to jurisdictional claims in published maps and institutional affiliations. 